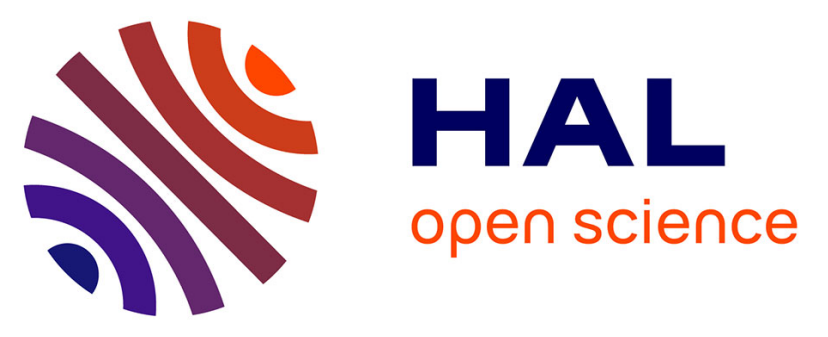

\title{
Impact of Silane Monolayers on the Adsorption of Streptavidin on Silica and Its Subsequent Interactions with Biotin: Molecular Dynamics and Steered Molecular Dynamics Simulations
}

\author{
Solène Lecot, Yann Chevolot, Magali Phaner-Goutorbe, Christelle \\ Yeromonahos
}

\section{To cite this version:}

Solène Lecot, Yann Chevolot, Magali Phaner-Goutorbe, Christelle Yeromonahos. Impact of Silane Monolayers on the Adsorption of Streptavidin on Silica and Its Subsequent Interactions with Biotin: Molecular Dynamics and Steered Molecular Dynamics Simulations. Journal of Physical Chemistry B, 2020, 124, pp.6786 - 6796. 10.1021/acs.jpcb.0c04382 . hal-03214424

\author{
HAL Id: hal-03214424 \\ https://hal.science/hal-03214424
}

Submitted on 1 May 2021

HAL is a multi-disciplinary open access archive for the deposit and dissemination of scientific research documents, whether they are published or not. The documents may come from teaching and research institutions in France or abroad, or from public or private research centers.
L'archive ouverte pluridisciplinaire HAL, est destinée au dépôt et à la diffusion de documents scientifiques de niveau recherche, publiés ou non, émanant des établissements d'enseignement et de recherche français ou étrangers, des laboratoires publics ou privés. 


\section{B: Biomaterials and Membranes}

\section{Impact of Silane Monolayers on the Adsorption of Streptavidin on Silica and Its Subsequent Interactions with Biotin: Molecular Dynamics and Steered Molecular Dynamics Simulations}

Solène Lecot, Yann Chevolot, Magali Phaner-Goutorbe, and Christelle Yeromonahos

J. Phys. Chem. B, Just Accepted Manuscript • DOI: 10.1021/acs.jpcb.0c04382 • Publication Date (Web): 14 Jul 2020

Downloaded from pubs.acs.org on July 22, 2020

\section{Just Accepted}

"Just Accepted" manuscripts have been peer-reviewed and accepted for publication. They are posted online prior to technical editing, formatting for publication and author proofing. The American Chemical Society provides "Just Accepted" as a service to the research community to expedite the dissemination of scientific material as soon as possible after acceptance. "Just Accepted" manuscripts appear in full in PDF format accompanied by an HTML abstract. "Just Accepted" manuscripts have been fully peer reviewed, but should not be considered the official version of record. They are citable by the Digital Object Identifier (DOI®). "Just Accepted" is an optional service offered to authors. Therefore, the "Just Accepted" Web site may not include all articles that will be published in the journal. After a manuscript is technically edited and formatted, it will be removed from the "Just Accepted" Web site and published as an ASAP article. Note that technical editing may introduce minor changes to the manuscript text and/or graphics which could affect content, and all legal disclaimers and ethical guidelines that apply to the journal pertain. ACS cannot be held responsible for errors or consequences arising from the use of information contained in these "Just Accepted" manuscripts. 


\title{
Impact of Silane Monolayers on the Adsorption of
}

\author{
Streptavidin on Silica and its Subsequent
}

\section{Interactions with Biotin: Molecular Dynamics and}

\section{Steered Molecular Dynamics Simulations}

\author{
Solène Lecot ${ }^{\perp}$, Yann Chevolot ${ }^{\perp}$, Magali Phaner-Goutorbe ${ }^{\perp *}$, Christelle Yeromonahos $^{\perp *}$ \\ ${ }^{\perp}$ Université de Lyon, Institut des Nanotechnologies de Lyon UMR 5270, Ecole Centrale de \\ Lyon, 36 avenue Guy de Collongue, 69134 Ecully, France
}

\section{* Corresponding Authors}

Christelle Yeromonahos: christelle.yeromonahos@ec-lyon.fr, + 33472186235

Magali Phaner-Goutorbe: magali.phaner-goutorbe@ec-lyon.fr, +33 472186232 


\begin{abstract}
Protein adsorption on surfaces is used in analytical tools as an immobilization mean to trap the analyte to be detected. However, protein adsorption can lead to a conformational change in the protein structure, resulting in a loss of bioactivity. Here, we study the adsorption of the Streptavidin

- Biotin complex on amorphous $\mathrm{SiO}_{2}$ surfaces functionalized with five different silane selfassembled monolayers by all-atom Molecular Dynamics simulations. We find that the Streptavidin global conformational change increases linearly with the adsorption energy, which depends, as well as the nature of residues with high mobility, on the alkyl chain length and head group charge of silane molecules. Effects on interactions with Biotin are further investigated by Steered Molecular Dynamics (SMD) simulations, which mimics Atomic Force Microscope (AFM) spectroscopy with the Biotin attached on the tip. We show the combined effects of adsorptioninduced global conformational changes and of the position of residues with high mobility on the force of Biotin detachment. By comparing our results to experimental and SMD detachment forces obtained in water, without any surface, we conclude that silane with uncharged and short alkyl chains allow Streptavidin immobilization, with high adsorption energy, while keeping Biotin interactions better than silanes with long alkyl chains or charged head-groups.
\end{abstract}




\section{INTRODUCTION}

Adhesion of protein on surface has major issues in many applications. Indeed, depending on the final orientation or conformation, protein adsorption can lead to inflammatory response at the surface of an implant. Furthermore, protein adsorption is also used in analytical devices as a simple immobilization mean allowing for the subsequent capture of the analyte to be detected. ${ }^{1}$ Consequently, it is crucial to understand the surface physico-chemical parameters that govern the conformation of proteins adsorbed on surfaces.

Interactions with proteins were investigated for a large range of surfaces, including polymers ${ }^{2}$, graphene $^{3}$ and Self-Assembled Monolayers (SAM). For instance, the adsorption of blood plasma proteins on alkanethiol SAM was investigated by Atomic Force Microscopy, demonstrating that adhesion force varies as a function of alkanethiol terminal group (-COOH, $\left.-\mathrm{OH},-\mathrm{NH}_{2},-\mathrm{CH}_{3}\right)$ and protein. ${ }^{4}$ Among surfaces, silane SAM are promising ones to monitor the surface properties of oxide materials and to control protein adsorption on their surface. ${ }^{5-7}$ Indeed, the nature of the head group and the length of the alkyl chain of silane molecules determine the surface charge and its hydropathy.

Molecular Dynamics (MD) simulations are well suited to investigate protein adsorption on surfaces, as they give information about protein - surface interactions. Furthermore, the conformational changes induced by adsorption on surfaces can be deciphered at atomic scale. ${ }^{8} \mathrm{MD}$ simulation studies were performed with various proteins and peptides on crystalline surfaces, including $\mathrm{Au}^{9-10} \mathrm{TiO}_{2}{ }^{11}, \mathrm{SiO}_{2}{ }^{12-14}$, graphite ${ }^{11}$ and polymer ${ }^{15}$. The adsorption of proteins and peptides was also reported on $\mathrm{SAM}^{16}$, especially on thiols-based monolayers. Alkanethiol monolayers were investigated with different terminal groups $\left(-\mathrm{COOH},-\mathrm{OH},-\mathrm{NH}_{2},-\mathrm{CH}_{3}\right)$, i.e. surfaces with various charge and hydropathy properties. ${ }^{17-25}$ Alkanethiol molecule orientation and 
in-contact water organization were deciphered, as well as properties of protein adsorption including orientation ${ }^{26}$, conformational changes, interaction energy and contact surface. For instance, it was demonstrated that Amyloid- $\beta$ peptide adsorption on an alkanethiol monolayer induced an increase in the Root-Mean-Square-Deviation of atomic positions (RMSD) value, regardless of terminal group. Furthermore, the total interaction energy between the peptide and alkanethiol molecules was higher for $-\mathrm{COOH}$ and $-\mathrm{NH}_{2}$ than for $-\mathrm{CH}_{3}$ terminated molecules, while the peptide displayed the weakest adsorption on $-\mathrm{OH}$ alkanethiol monolayer. ${ }^{19}$ Recently, the possibility to control protein adsorption on a mixed alkanethiol monolayer by applying an electric field was demonstrated. ${ }^{27}$

Streptavidin is a tetrameric protein involved in the well-known Streptavidin - Biotin complex. The complex leads to one of the strongest existing non-covalent bonding, as Biotin forms hydrogen bonds with eight residues of Streptavidin. This system was already studied, in water without any surface, by MD simulations. ${ }^{28,29}$ The study of wild-type Streptavidin and mutants demonstrated that the strong binding affinity between Streptavidin and Biotin is due to strong cooperativity between residues. ${ }^{30}$ Also, the essential role of the conformation of the loop 3-4 in its ability to interact with Biotin and retain it inside the binding pocket was demonstrated. ${ }^{31}$ Furthermore, the Streptavidin conformational changes due to adsorption on crystalline surfaces were deciphered. ${ }^{11}$ However, to our knowledge, the Streptavidin adsorption on silane monolayers has never been investigated.

Experimentally, the Atomic Force Microscopy (AFM) and specially in the Single Molecule Force Spectroscopy (SMFS) mode, has proven to be a well-adapted technique to explore the forces and dynamics of the interaction between individual ligands and receptors for molecular recognition studies. ${ }^{32-34}$ The Streptavidin - Biotin complex has extensively been used as a model system to 
investigate the ability of the SMFS-AFM technique..$^{28,32,35-38}$ Streptavidin and Biotin are attached on solid substrate and on the AFM tips and the rupture force, binding energy and rupture length of Streptavidin - Biotin complex are measured, giving insight into the complex unbinding pathway. The different studies have demonstrated a large variability in the rupture forces depending on the chemical protocols used to link the biomolecules on the tip and on the contact surface but also due to the difference in the experimental parameters chosen for the AFM force curve acquisition. In particular, the loading rate (retracting velocity multiplied by the spring constant) influences drastically the rupture force. ${ }^{39}$ Thus, effect of the loading rate on the measured rupture force was deciphered from low to very high pulling velocities (up to $30000 \mu \mathrm{m} / \mathrm{s}$ ) by using High-Speed Force Spectroscopy. ${ }^{39}$

Non-equilibrium Steered Molecular Dynamics (SMD) simulations allow to mimic the AFM experiment by pulling at a specific constant velocity on one of the two biomolecules involved in the biomolecular interaction. In the understanding of Streptavidin - Biotin unbinding process, it has been proven to supplement AFM experiments, in the identification of rupture force, unbinding pathway and energy landscape. ${ }^{39,40}$ By combining AFM experiments and SMD simulations, it was shown that the measured bond strength increases with the loading rate ${ }^{40}$ and that different intermediates states are involved in the unbinding process, depending on the magnitude of the pulling velocity. ${ }^{39}$ Usually, Streptavidin center-of-mass (COM) is fixed, while Biotin is pulled along a defined reaction coordinate by applying an external force. Recently, Sedlak et al. investigated the impact of tethering one terminus of monovalent Streptavidin instead of its COM, to mimic the immobilization of Streptavidin with a covalent bond. It was demonstrated that the rupture force is twice higher when Streptavidin is fixed with its C-terminus than with its Nterminus, due to structural changes and partial unfolding. ${ }^{41}$ Moreover, the conformational changes 
induced in a tetrameric Streptavidin by attachment of the C-terminus of a different subunit were shown to result in a change of the unbinding pathway and in a fourfold decrease of the unbinding force. ${ }^{42}$ However, to our knowledge, the impact of Streptavidin conformational change, due to its adsorption on a silane monolayer, on its interaction with Biotin has never been explored.

In this work, we perform classical MD simulations to investigate the adsorption of Streptavidin on different types of silane monolayers and the resulting conformational changes. Then, we further investigate its interactions with Biotin by SMD simulations. The detachment of the Biotin from the Streptavidin is simulated such as in AFM spectroscopy experiments with the Biotin at the extremity of the tip and the Streptavidin on the surface. These simulations allow to investigate the effects of adsorption of Streptavidin on its detachment force with Biotin.

\section{METHODS}

We performed a two-step simulation: first, we studied the conformation of Streptavidin adsorbed on different silane monolayers and then, we completed SMD simulations to explore the effect of silane monolayers on the detachment of Biotin from Streptavidin.

1.1 System Description. We investigated six different systems. One system was the extensively investigated Streptavidin - Biotin complex in water ${ }^{29,39,40}$, while the five other systems included an additional amorphous $\mathrm{SiO}_{2}$ layer functionalized with different silane monolayers (Figure 1). 
(a)

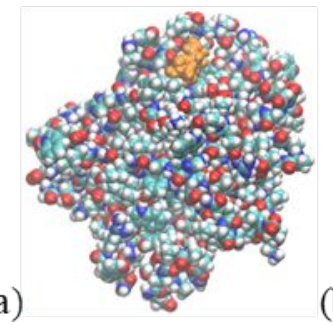

(d)

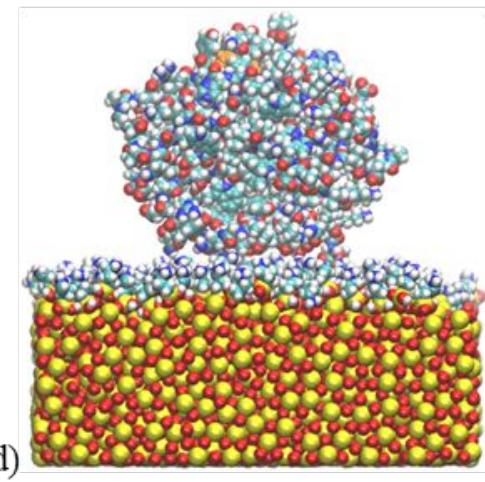

(b)
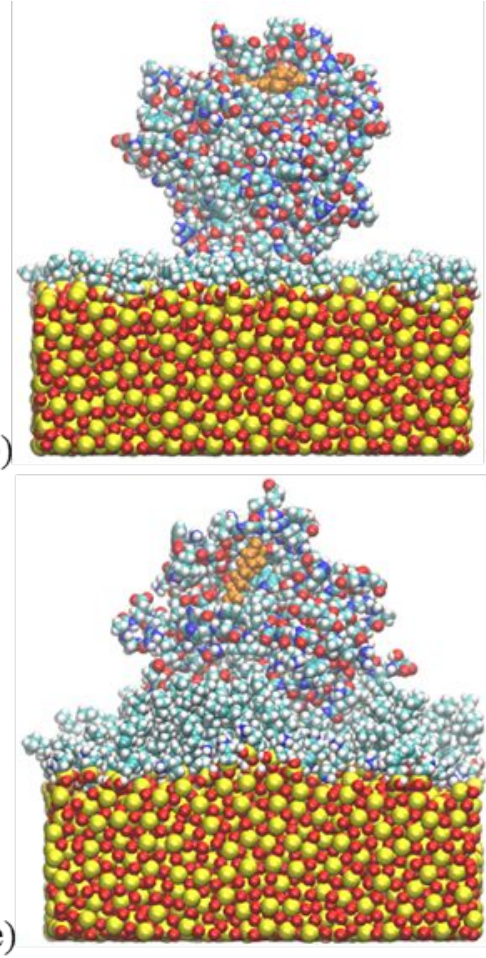

(c)

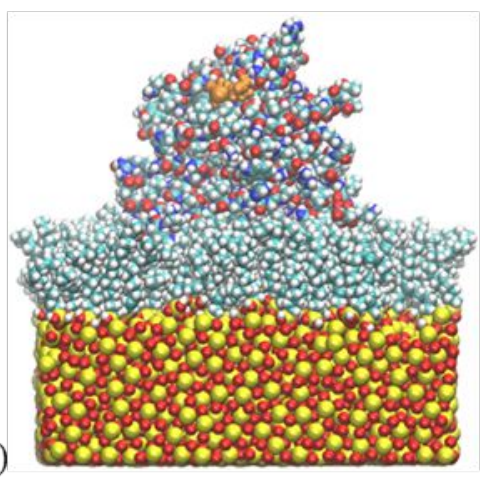

(f)

Figure 1. Images of the six different systems after 100 ns MD simulations: (a) Streptavidin Biotin complex in water and Streptavidin - Biotin complex adsorbed on silane monolayers (b) $\mathrm{CH}_{3}$ short, (c) $\mathrm{CH}_{3}$ long, (d) $\mathrm{NH}_{3}{ }^{+}$, (e) mix long and (f) mix short. Atoms are shown in yellow (silicon), red (oxygen), cyan (carbon), and white (hydrogen) and blue (nitrogen). Biotin is shown in orange.

The Streptavidin - Biotin complex was based on the PDB structure $3 \mathrm{RY} 2^{43}$, including a dimeric Streptavidin and two Biotin molecules. Only one Biotin was kept, located in the binding pocket of Streptavidin chain $A$. The OPLS all-atom force field ${ }^{44}$ was used for Streptavidin, while the Biotin force field was obtained from the ATB facilities. ${ }^{45,46}$

The amorphous silica structure was taken from Roscioni et al. ${ }^{47}$ Silane molecules (even in the case of the mixed SAMs) are initially placed randomly in the surface plane ( $x y$ plane) by a homemade Python code, at a distance of $0.3 \mathrm{~nm}$ above the surface, and by ensuring a minimum in-plane 
distance of $0.3 \mathrm{~nm}$ between silane molecules. After energy minimization, the silane molecules are close enough to the surface, so a position restriction is applied in the direction normal to the surface but not in the $\mathrm{x}$ and $\mathrm{y}$ directions. As a consequence, molecules can diffuse and reorganize. The structure of the silane monolayers obtained with this methodology have been characterized and validated through comparison with experimental data (data not shown).

Three silane molecules were involved in the different silane monolayers: octadecyltrimethoxysilane $\left(\mathrm{C}_{21} \mathrm{H}_{46} \mathrm{O}_{3} \mathrm{Si}\right.$ named $\mathrm{CH}_{3}$ long), n-butyltrimethoxysilane $\left(\mathrm{C}_{7} \mathrm{H}_{18} \mathrm{O}_{3} \mathrm{Si}\right.$ named $\mathrm{CH}_{3}$ short) and 3-aminopropyltriethoxysilane $\left(\mathrm{C}_{9} \mathrm{H}_{24} \mathrm{NO}_{3} \mathrm{Si}\right.$ named $\left.\mathrm{NH}_{3}^{+}\right)$. Silane molecules, with the trisilanol structure obtained after hydrolylation, were positioned on the $\mathrm{SiO}_{2}$ surface following the method proposed by Roscioni et al. ${ }^{47}$ Indeed, the bonding to the $\mathrm{SiO}_{2}$ layer is modelled, by removing the hydrogen atom from one of the three hydroxyl groups, and by using high Lennard-Jones and electrostatic potentials between the oxygen atom of silane molecule and a silicon atom of the $\mathrm{SiO}_{2}$ layer. Only one of the three silanols was reacted. The two others remained unreacted to behave similarly to monofunctionnal silanes.

As summarized in Table 1, five different silane monolayers were studied, one per silane molecule and two mixed layers, all with a coverage of 3 molecules $/ \mathrm{nm}^{2}$. Force-field parameters for $\mathrm{SiO}_{2}$ layer and silane molecules were adapted from recent studies ${ }^{47,48}$ and from the OPLS allatom force field (see details in Supporting Information, page S2). Silane monolayers density and organization were consistent with experimental results and other MD studies in terms of coverage, tilt angle, gauche defects and in-plane organization (data not shown). 
Table 1. Composition of the Five Different Silane Monolayers

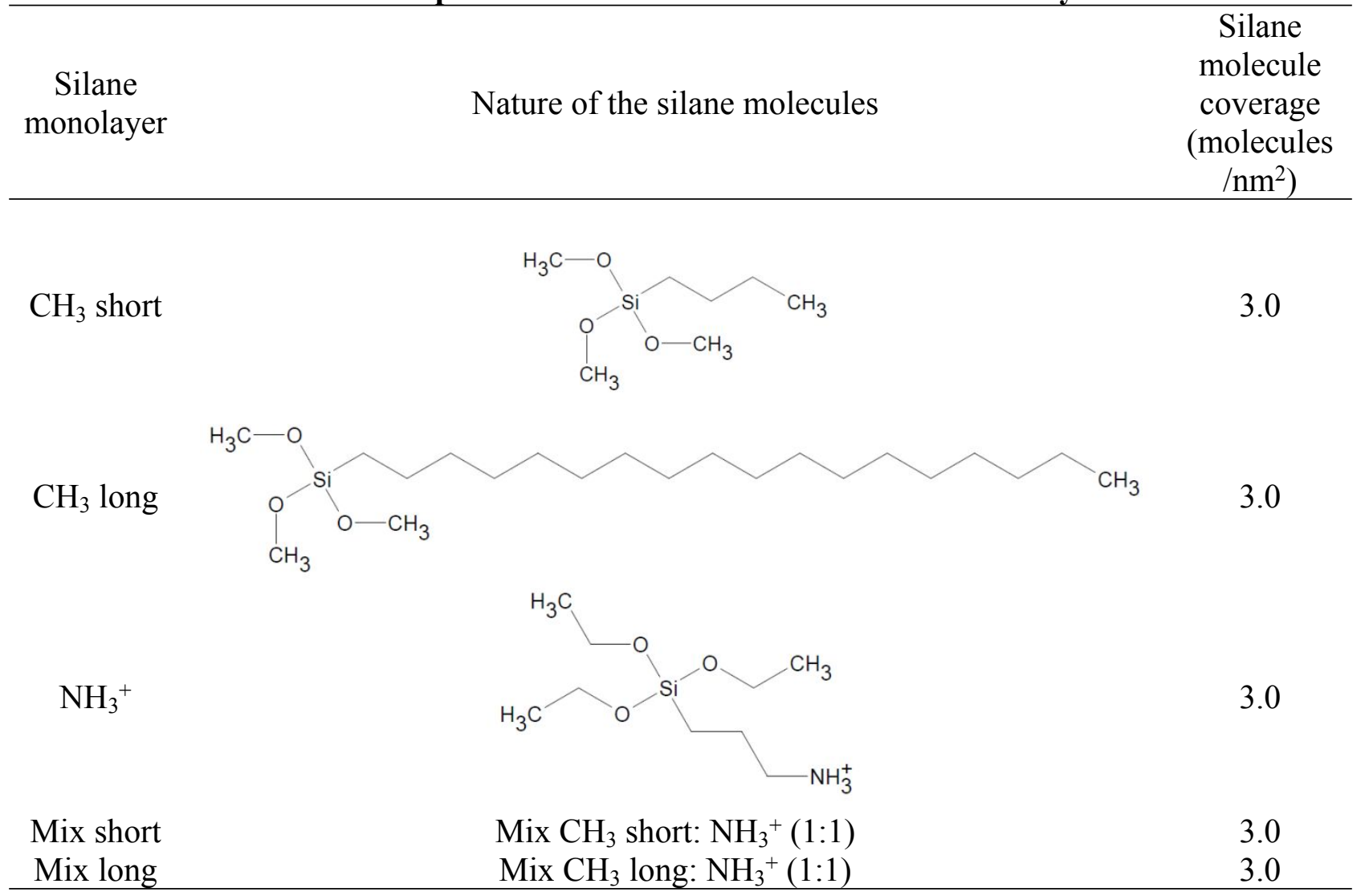

Water model TIP4P49, as well as $\mathrm{Na}^{+}$and $\mathrm{Cl}^{-}$ions, were described with OPLS all-atom force field. Ions were added at a concentration of $150 \mathrm{mmol} / \mathrm{L}$ to mimic physiological conditions and to compensate charges. Furthermore, a Lennard-Jones (LJ) wall was added at the top of the box to prevent any interaction between water and the bottom side of the $\mathrm{SiO}_{2}$ surface. Thus, the system only uses periodic boundary conditions in $\mathrm{x}$ and $\mathrm{y}$ directions. The force field parameters were taken from Kitabata et al. for the LJ wall. ${ }^{50}$

\subsection{Simulation Details}

Adsorption of Streptavidin on Silane Monolayers. The simulations were performed with the Gromacs simulation package, version 5.1.351 and visualization was done using the VMD 
software package version 1.9.52 Firstly, energy minimization was performed with the Steepest Descent method, followed by NVT and NPT equilibrations of 100 ps each, with a targeted temperature of $300 \mathrm{~K}$. Then 5 independent production runs of $100 \mathrm{~ns}$ each were carried out for the system in water (without surface) and 10 independent production runs of $100 \mathrm{~ns}$ each were carried out for all systems with a surface. The integration of the equations of motion was done using a leap-frog algorithm and a time step of 2 fs. A LINCS algorithm was used to apply constraint to bond parameters. Temperature was maintained at $300 \mathrm{~K}$ with a Nose-Hoover thermostat and a time constant of 0.4 ps. The pressure was kept at 1 bar using a Parrinello-Rahman barostat, with a time constant of 2 ps. Long-range electrostatic interactions were calculated with the particle-mesh Ewald method ${ }^{53}$ and a cutoff of $1 \mathrm{~nm}$. The same cutoff was used for LJ potentials.

SMD Simulations. We performed non-equilibrium SMD simulations, where an external force is applied to Biotin to unbind it from Streptavidin. The COM of Streptavidin was fixed for the system in water, but no position restriction was applied to Streptavidin for all the systems with a surface. Only the Van der Waals and electrostatic interactions between Streptavidin and silane molecules prevented from Streptavidin desorption while Biotin was pulled away. Force was applied to Biotin by a harmonic potential with a spring constant $\mathrm{k}=100 \mathrm{pN} / \mathrm{nm}^{39}$ and a velocity $v$ $=2 \mathrm{~m} / \mathrm{s}$. To reproduce AFM experiments, Biotin was pulled away from Streptavidin in the direction normal to the surface. However, the impact of the pulling direction was considered, as discussed below. Indeed, the choice of the ligand pulling direction can impact the rupture force value and the unbinding process obtained with SMD simulations, as shown by Júnior et al. ${ }^{54}$ The final state of protein adsorption simulations was used as the starting configuration for SMD simulations. A time step of 1 fs was used for the integration of equations of motion. SMD simulations were performed for at least $4 \mathrm{~ns}$ (300 simulations in total). 


\subsection{Analysis.}

Adsorption of Streptavidin on Silane Monolayers. The investigated parameters were the RootMean-Square Deviation (RMSD) and the Root-Mean-Square Fluctuation (RMSF) of Streptavidin, and the Van der Waals and electrostatic contributions to interaction energies between Streptavidin and silane molecules. The given values were averaged over the last $10 \mathrm{~ns}$ of the simulations and the error bars correspond to the standard deviation calculated from the simulation replicates. We also defined the contact surface at the final state of the simulation. Streptavidin atoms were considered in contact with the silane monolayer if they were located at less than $0.3 \mathrm{~nm}$ from one atom of a silane molecule. Furthermore, the Streptavidin residues linked to the silane monolayer were defined as the residues in contact with silane molecules at final state. 10 simulation replicates were performed for each system. Thus, Streptavidin residues are considered in contact with the surface if they are involved in more than half of the simulation replicates.

SMD Simulations. The rupture force was defined from the force - time curve as the highest force applied on Biotin before detachment. The rupture force and time of rupture were determined for each simulation replicate. Mean value, standard deviation and histograms of the rupture force were calculated from the replicates of each system.

\section{RESULTS AND DISCUSSION}

2.1. Initial Orientation of Streptavidin. Previous studies have shown that protein initial orientation impacts its adsorption on a surface, by changing the interaction energy and the nature of residues interacting with the surface. ${ }^{10,11,16,26}$ Here, simulations of Streptavidin adsorption on $\mathrm{SiO}_{2}$ surface functionalized with $\mathrm{NH}_{3}{ }^{+}$silane molecules were performed with three different initial orientations, as depicted in Figure 2. Orientation 2 was defined from orientation 1 by a $180^{\circ}$ 
rotation of Streptavidin along the $x$-axis and orientation 3 by a $270^{\circ}$ rotation along the $y$-axis. Simulations of protein adsorption were all performed for $100 \mathrm{~ns}$, allowing stabilization of the total VdW and elec interaction energy (Supporting Information, Figure S3). The following interaction energies were obtained between Streptavidin and $\mathrm{NH}_{3}{ }^{+}$silane molecules: $-158 \pm 16 \mathrm{kcal} / \mathrm{mol},-196$ $\pm 65 \mathrm{kcal} / \mathrm{mol}$ and $-227 \pm 83 \mathrm{kcal} / \mathrm{mol}$ for orientation 1,2 and 3 , respectively. Although the effect of initial orientation on the total $\mathrm{VdW}$ and elec interaction energy is low, orientation 3 leads to the most stable adsorption of Streptavidin. As all the surfaces studied are to some extent hydrophobic (with different degrees of hydrophobicity), we have assumed that orientation 3 is favorable for all silane monolayers. Thus, orientation 3 was chosen for all the following simulations in this study, whatever the nature of the silane monolayer.

Furthermore, this assumption is supported by the electrostatic potential distribution on the Streptavidin molecular surface (Supporting Information, Figures S1 and S2). Indeed, in the initial orientation 3, residues with different electrostatic potential (positive, negative, close to zero) are pointing towards the silane monolayer. After adsorption, conformational changes and small reorientation of the Streptavidin are observed. Thus, the Streptavidin contact surface with $\mathrm{NH}_{3}{ }^{+}$ silane molecules is made of residues with negative electrostatic potential, while the contact surface with uncharged silane molecules is mainly made of residues with electrostatic potential close to zero. In the case of the initial orientation 2 , residues with positive electrostatic potentials mainly, point towards the silane monolayer. So, these results suggest that indeed the orientation 2 is a less favourable initial orientation than the orientation 3. However, the electrostatic potential distribution does not allow to clearly confirm the assumption that the orientation 3 is more favourable than the orientation 1 , for all the silane monolayers studied. 
(a)

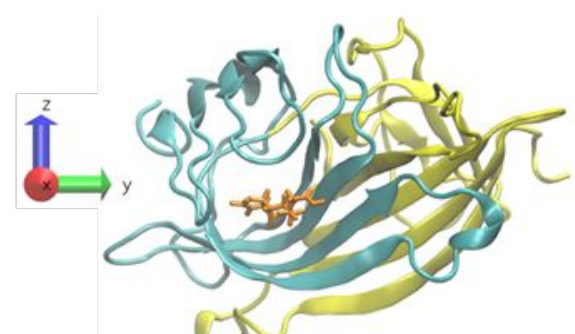

(b)

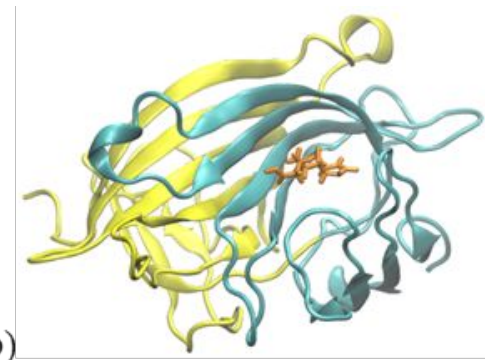

(c)

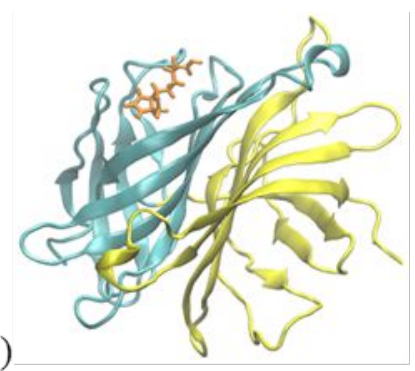

Figure 2. Streptavidin orientation above the $\mathrm{NH}_{3}{ }^{+}$monolayer: (a) orientation 1 (reference), (b) orientation 2 (rotation of $180^{\circ}$ along the $x$-axis) and (c) orientation 3 (rotation of $270^{\circ}$ along the $y$-axis). Chain $A$ of Streptavidin is shown in cyan; chain $B$ is in yellow and Biotin in orange.

\subsection{Streptavidin Conformational Change Due to Its Adsorption on Silane Monolayers.}

Interactions between Streptavidin and Silane Molecules. The interactions between Streptavidin and silane monolayers are characterized by the total VdW and elec interaction energy and by the contact area between the protein and silane molecules (Table 2). Interactions between Streptavidin and the amorphous $\mathrm{SiO}_{2}$ layer are deciphered in Supporting information, Table $\mathrm{S} 1$. The contact area is defined by the number of atoms of Streptavidin in contact with silane molecules and by the nature of the residues involved. The five silane monolayers studied involve three different silane molecules which differ by their alkyl chain length and head-group charge. It results in different surface charges and hydrophobicity. These properties impact the type of interactions between Streptavidin and silane molecules. 


\begin{tabular}{|c|c|c|c|}
\hline $\begin{array}{l}\text { Silane } \\
\text { monolayer }\end{array}$ & $\begin{array}{l}\text { Total VdW and } \\
\text { elec interaction } \\
\text { energy between } \\
\text { Streptavidin and } \\
\text { silane molecules } \\
\quad(\mathrm{kcal} / \mathrm{mol})\end{array}$ & $\begin{array}{c}\text { Number of } \\
\text { Streptavidin } \\
\text { atoms in contact } \\
\text { with silane } \\
\text { molecules }\end{array}$ & $\begin{array}{c}\text { Residues of Streptavidin linked to the } \\
\text { silane molecules }\end{array}$ \\
\hline $\mathrm{CH}_{3}$ short & $-113 \pm 22$ & $64 \pm 18$ & $\begin{array}{c}A: \text { Ala65, Thr66, Asp67, Gly68-B: } \\
\text { Glu51, Asn82, Tyr83, Arg84, Asn85, } \\
\text { His87 }\end{array}$ \\
\hline $\mathrm{CH}_{3}$ long & $-170 \pm 42$ & $154 \pm 37$ & $\begin{array}{c}\text { A: Ala35, Asp36, Ser62, Ala63, } \\
\text { Pro64, Ala65, Thr66, Asp67, Ser69, } \\
\text { Gly99, Ala100 - B: Gln24, Leu25, } \\
\text { Val47, Asn49, Glu51, Arg53, Asn81, } \\
\text { Asn82, Tyr83, Arg84, Asn85, Ala86, } \\
\text { His87, Ser112, Thr114, Thr115, } \\
\text { Ala117, Asn118 }\end{array}$ \\
\hline $\mathrm{NH}_{3}{ }^{+}$ & $-197 \pm 51$ & $24 \pm 7$ & $A:$ Asp67 - B: Glu51 \\
\hline Mix short & $-147 \pm 38$ & $30 \pm 14$ & $\begin{array}{c}A: \text { Asp67, Gly68 - B: Glu51, Glu116 } \\
\text { B: Tyr22, Gln24, Leu25, Gly26, }\end{array}$ \\
\hline Mix long & $-186 \pm 61$ & $128 \pm 42$ & $\begin{array}{l}\text { Ser27, Ile30, Tyr43, Glu44, Ala46, } \\
\text { Val47, Asn49, Glu51, Asn82, Tyr83, } \\
\text { Arg84, Asn85, Val133, Pro135 }\end{array}$ \\
\hline
\end{tabular}

The lowest number of Streptavidin atoms interacting with silane molecules is obtained for $\mathrm{NH}_{3}{ }^{+}$silane monolayer (24 \pm 7 atoms), while the higher total $\mathrm{VdW}$ and elec interaction energy is reached for the same silane monolayer $(-197 \pm 51 \mathrm{kcal} / \mathrm{mol})$. Thus, the energy associated to each individual interaction is high. It corresponds to hydrogen bonds $(6.7 \pm 2.7$ bonds $)$ and electrostatic interactions. Indeed, $\mathrm{NH}_{3}{ }^{+}$silane molecules are more specifically in contact with residues Asp67 and Glu51 which are both hydrophilic and negatively charged. Regarding the $\mathrm{CH}_{3}$ short monolayer, the contact surface is higher than for $\mathrm{NH}_{3}{ }^{+}$but the total $\mathrm{VdW}$ and elec interaction energy is lower, which means that the energy associated to each individual interaction is lower, in agreement with Van der Waals interactions. Streptavidin residues interacting with $\mathrm{CH}_{3}$ short silane 
molecules display various charge and hydropathy properties. For instance, negatively charged residue Glu51, positively charged Arg84 and non-polar Ala65 are all involved in interactions with $\mathrm{CH}_{3}$ short silane monolayer. Regarding the mix short monolayer, the total VdW and elec interaction energy is approximately the mean value of $\mathrm{NH}_{3}{ }^{+}$and $\mathrm{CH}_{3}$ short uniform monolayers. Also, the contact surface is lower than for $\mathrm{CH}_{3}$ short monolayer, as $\mathrm{NH}_{3}{ }^{+}$silane molecules induce a repulsion of some Streptavidin residues. For instance, positively charged residue Arg84 is not interacting with the mix short monolayer (because of the repulsion induced by the $\mathrm{NH}_{3}{ }^{+}$headgroups of the silane molecules), while it is involved in interactions with the $\mathrm{CH}_{3}$ short monolayer through interactions between the methylene groups of Arg84 and the silane alkyl chains. Negatively charged and hydrophilic residues Asp67, Glu51 and Glu116 are specifically interacting with $\mathrm{NH}_{3}{ }^{+}$silane molecules of mix short monolayer.

The contact area is very high for $\mathrm{CH}_{3}$ long molecules as Streptavidin enters into the silane monolayer (Figure 1). Van der Waals interactions are established between Streptavidin and $\mathrm{CH}_{3}$ long silane molecules, with no selection on the type of residues: hydrophobic and non-polar residues (Ala, Val, Leu) interact with silane molecules, as well as hydrophilic or charged residues (Arg, Asn, Asp, His). Regarding the mix long silane monolayer, steric hindrance due to $\mathrm{CH}_{3}$ long silane molecules partially prevents interactions between Streptavidin and $\mathrm{NH}_{3}{ }^{+}$silane molecules but does not remove them completely. Contact area and energy are close to the values obtained for $\mathrm{CH}_{3}$ long molecules. Also, we observe that the nature of residues in contact with the surface is less reproducible with the mix long surface than with the other surfaces, especially for chain $A$. Indeed, no residue is involved in more than half of the simulation replicates. 
Our results suggest that long alkyl chains yield highest contact area, while surface charges tend to decrease the contact area. Also, the total $\mathrm{VdW}$ and elec interaction energy is governed more by surface charges than by contact area.

RMSD. The evolution of Streptavidin RMSD with time is depicted in Figure 3. As expected, the lowest RMSD value at final state is obtained for the system in water, as there is no conformational change induced by a surface. A value of $4.1 \pm 0.3 \AA$ is obtained, which is in accordance with a recent MD study. ${ }^{11}$ When Streptavidin is adsorbed on a surface, our RMSD values vary from $4.2 \pm 0.5 \AA$ on $\mathrm{CH}_{3}$ short monolayer to $5.0 \pm 0.9 \AA$ on $\mathrm{NH}_{3}{ }^{+}$monolayer. Also, the higher the total VdW and elec interaction energy between Streptavidin and the silane monolayer is, the stronger the Streptavidin global deformation is.

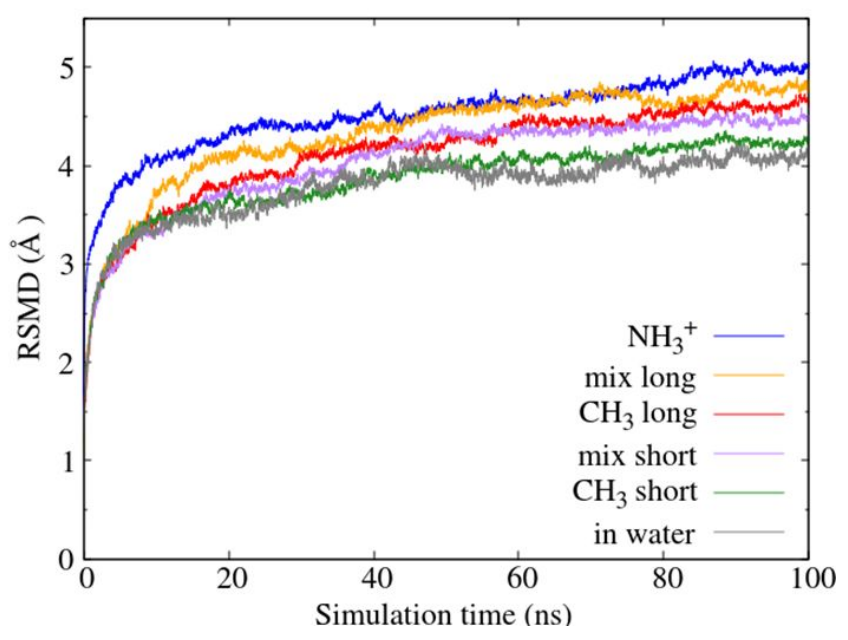

Figure 3. Evolution of Streptavidin Root-Mean-Square Deviation (RSMD) in water and during its adsorption on silane monolayers.

Recent MD simulations have established that Streptavidin adsorption on crystalline surfaces such as graphite and $\mathrm{TiO}_{2}$ leads to very high conformational changes, with RMSD values in the range 15 - $40 \AA^{11}$, as Streptavidin is spreading over the surface. Our results show that silane monolayers lead to RMSD values closer to the one obtained in water than to the ones obtained on 
graphite and $\mathrm{TiO}_{2}$ surfaces. It can be explained by the narrower contact area between Streptavidin and silane monolayer than between Streptavidin and graphite or $\mathrm{TiO}_{2}$ surfaces.

Thus, Streptavidin adsorption on silane monolayers leads to global conformational changes, as RMSD values are higher than values obtained in water. However, these conformational changes are much lower than those observed following its adsorption on unfunctionalized crystalline surfaces. In the following, we further characterize the conformational changes of Streptavidin through the Root Mean Square Fluctuations (RMSF) of the most flexible residues.

RMSF. The change in Streptavidin conformation due to its adsorption on different silane monolayers is further investigated with the RMSF, which gives insight into the mobility of each residue of a protein. A high RMSF value demonstrates a high residue flexibility. ${ }^{55,56}$ RMSF traces are depicted in Supporting Information, Figure S4. For all systems, individual RMSF values of Streptavidin residues are between $0.5 \AA$ and $4.5 \AA$ approximately. It is considered that a residue with RMSF $\geq 3 \AA$ shows a high flexibility. ${ }^{57}$ The locations of the most flexible residues on Streptavidin are shown in Figure 4. 
(a)
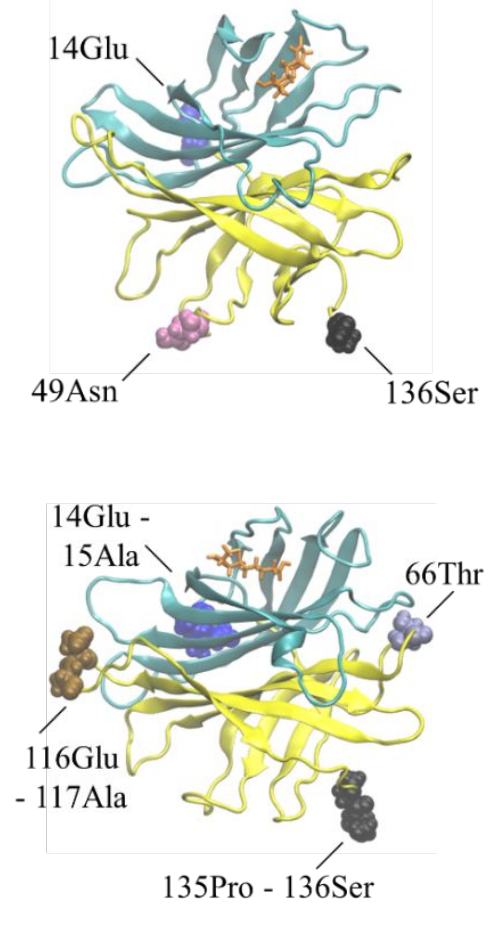

(d) (b)

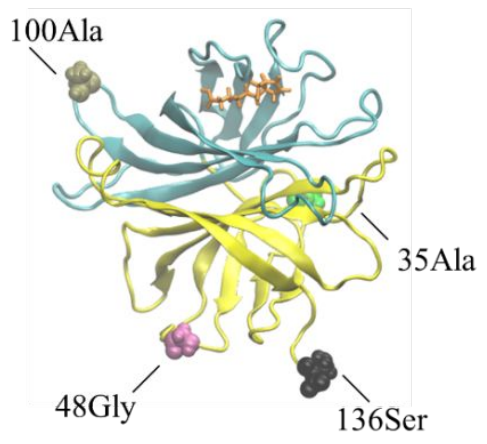

(c)

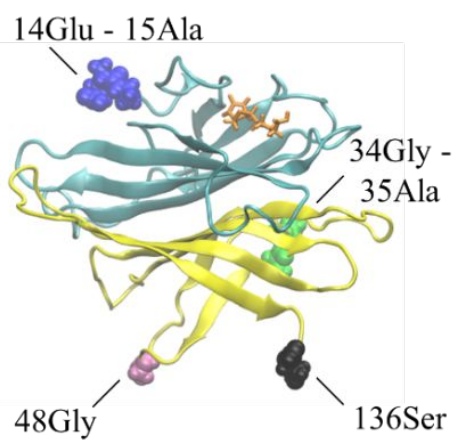

(f)

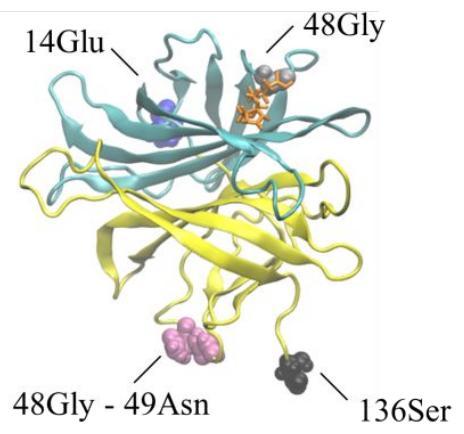

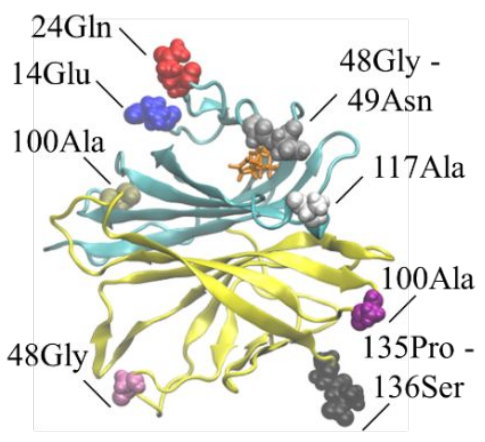

(e)

Figure 4. Localization of Streptavidin residues with high flexibility for the different systems: (a) in water (b) $\mathrm{CH}_{3}$ short, (c) $\mathrm{CH}_{3}$ long, (d) $\mathrm{NH}_{3}{ }^{+}$, (e) mix long and (f) mix short. Chain $A$ of Streptavidin is shown in cyan; chain $B$ is in yellow and Biotin in orange. Streptavidin residues with $\mathrm{RMSF} \geq 3 \AA$ are shown in other colors.

In water, without any surface, only three residues show a RMSF value larger than $3 \AA$, including 2 residues in chain $B$ (49Asn and 136Ser) and one residue in the N-terminus of chain $A$ (14Glu), far from the Biotin binding pocket. For all systems with a surface, there are more than three residues with high flexibility, in agreement with RMSD values. Streptavidin adsorption on $\mathrm{CH}_{3}$ short monolayer leads to a high mobility of 4 residues, including 3 residues in chain $B$ and only 1 hydrophobic residue 100Ala in chain $A$ far from the Biotin binding pocket. Regarding $\mathrm{CH}_{3}$ long monolayer, 6 residues show a high mobility, including only 2 residues in chain $A$, far from the Biotin binding pocket, the N-terminus of chain $A(14 \mathrm{Glu})$ and the neighboring hydrophobic 
15Ala residue. $\mathrm{NH}_{3}{ }^{+}$monolayer leads to a high mobility of 7 residues, only 2 of them are in chain $A$ far from the Biotin binding pocket, the 14Glu and the 15Ala residues. Regarding mix long monolayer, 10 residues have a flexibility higher than $3 \AA, 6$ of them are in chain $A$. Among them, 3 residues are located close to the Biotin binding pocket (24Gln, 48Gly and 49Asn). Eventually, mix short monolayer leads to a high flexibility of 5 residues, 2 of them are in chain $A$. One of them (48Gly) is located in the Biotin binding pocket and is in direct contact with Biotin.

Thus, the number and the nature of residues with high mobility are strongly affected by the adsorption of Streptavidin on a surface. The nature of the most flexible residues depends on the type of silane monolayer. Indeed, $\mathrm{CH}_{3}$ short, $\mathrm{CH}_{3}$ long and mix long monolayers induce a high flexibility of non-polar and hydrophobic Ala residues, while a high flexibility of negatively charged residue $117 \mathrm{Glu}$ and polar residue $66 \mathrm{Thr}$ is observed for $\mathrm{NH}_{3}{ }^{+}$silane monolayer. We do not observe a direct correlation between the RMSD value and the number of residues with high mobility. Indeed, the highest RMSD value is obtained for $\mathrm{NH}_{3}{ }^{+}$silane monolayer, but there are more residues with high flexibility for mix long monolayer. So, conformational changes are more diffuse in the whole protein with adsorption on $\mathrm{NH}_{3}{ }^{+}$silane monolayer, while they are more concentrated at some specific residues with adsorption on mix long silane monolayer. Regarding the location of Streptavidin residues with high mobility, for $\mathrm{CH}_{3}$ long, $\mathrm{CH}_{3}$ short and $\mathrm{NH}_{3}{ }^{+}$, only the N-terminus of chain $A$ display a high flexibility. On the contrary, for mix short and mix long monolayers, some residues with high mobility are in the Biotin binding pocket, such as 48Gly and 49Asn which belong to the loop 3-4. In the following, we investigate if these conformational changes induce a perturbation of Streptavidin - Biotin interactions.

2.3. Streptavidin-Biotin Unbinding. We have shown that the adsorption on a surface induces conformational changes in Streptavidin, which differ with the type of silane monolayer. To 
decipher their impact on interaction with Biotin, we performed SMD simulations on each system, where the starting configuration is the final state of Streptavidin adsorption simulations. Regarding the system in water, Biotin is pulled away from Streptavidin by applying a force on Biotin, while the COM of Streptavidin is fixed. For all systems with Streptavidin adsorption on a silane monolayer, there were no position restriction applied on Streptavidin, and we did not define any covalent bonding between Streptavidin and the surface. As well as for the system in water, force is applied on Biotin by applying a harmonic potential. We observe that Biotin is pulled away, while Streptavidin is never detached from the silane monolayer. Thus, the Van der Waals and electrostatic interactions established between Streptavidin and silane molecules are strong enough to prevent any Streptavidin desorption.

Pulling Direction for SMD Simulations. The Biotin is pulled away from Streptavidin along the surface normal, to reproduce an AFM experiment. For each silane monolayer, 2 or 3 SMD starting configurations are selected among adsorption simulation replicates. These configurations are characterized by the Streptavidin adsorption angle, i.e. the angle between the surface normal and the vector of Streptavidin COM to Biotin COM. 20 independent replicates of SMD simulations are performed on each configuration, with a pulling direction along the surface normal. The Streptavidin adsorption angle, the mean value of rupture force, and the histograms of rupture force (probability distribution) are presented in Supporting Information, Table S2 and Figure S5. No correlation is observed between Streptavidin adsorption angle and rupture force, and the histograms are overlapping for the different starting configurations on each silane monolayer. Therefore, in the following, the impact of different silane monolayers is compared with the mean rupture forces whatever the Streptavidin adsorption angle. This mimics the fact that AFM experimental force curves are performed at different points on a sample surface. 
Unbinding Time and Rupture Force. Typical unbinding curves for each system are shown in Figure 5 and mean values of unbinding time and rupture force are summarized in Table 3. Movies of unbinding processes for the six different systems are available in Supporting Information. For the system in water, a rupture force of $590 \pm 117 \mathrm{pN}$ is obtained for a loading rate of $2 \times 10^{11} \mathrm{pN} / \mathrm{s}$, which is consistent with the results previously obtained by Rico et al. ${ }^{39}$
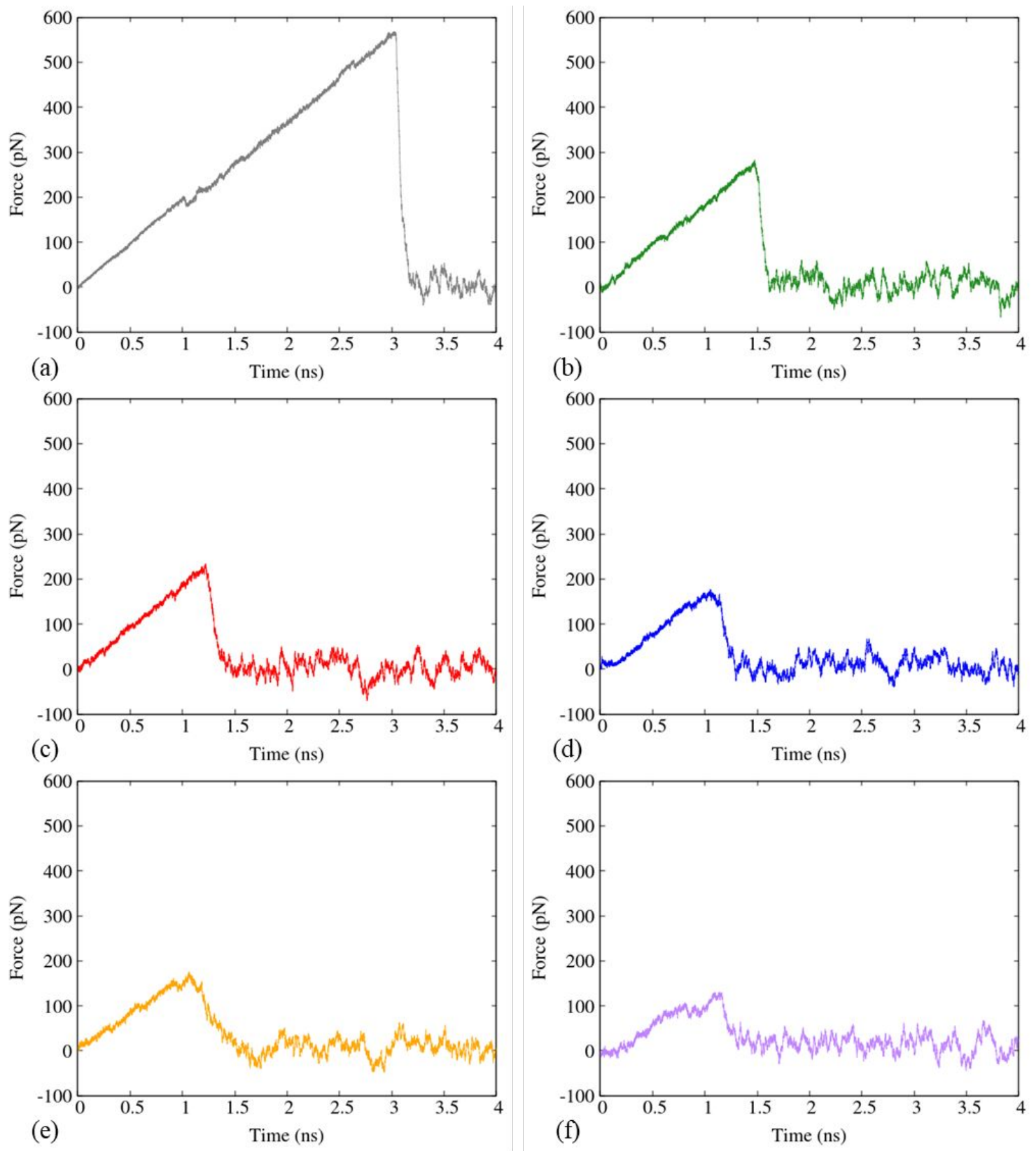
Figure 5. Typical force curves for the six different systems (a) in water (b) $\mathrm{CH}_{3}$ short, (c) $\mathrm{CH}_{3}$ long, (d) $\mathrm{NH}_{3}{ }^{+}$, (e) mix long and (f) mix short. The rupture force value obtained for the system in water is consistent with previous studies at the same loading rate. ${ }^{39}$ Lower values are obtained when Streptavidin is adsorbed on silane monolayers.

Table 3. Unbinding Time and Rupture Force Obtained with SMD Simulations for the Six Different Systems

\begin{tabular}{ccccccc}
\hline System & In water & $\mathrm{CH}_{3}$ short & $\mathrm{CH}_{3}$ long & $\mathrm{NH}_{3}{ }^{+}$ & Mix short & Mix long \\
\hline $\begin{array}{c}\text { Unbinding } \\
\text { time (ns) }\end{array}$ & $3.1 \pm 0.6$ & $1.6 \pm 0.4$ & $1.2 \pm 0.2$ & $1.0 \pm 0.3$ & $1.1 \pm 0.8$ & $1.0 \pm 0.2$ \\
$\begin{array}{c}\text { Rupture } \\
\text { force (pN) }\end{array}$ & $590 \pm 117$ & $278 \pm 91$ & $227 \pm 54$ & $167 \pm 60$ & $129 \pm 38$ & $166 \pm 47$ \\
\hline
\end{tabular}

As shown in Figure 5, the system in water corresponds to the highest rupture force. Thus, the adsorption of Streptavidin on a silane monolayer systematically induces a decrease in the rupture force. The second highest value is obtained with $\mathrm{CH}_{3}$ short silane monolayer. The rupture force is $278 \pm 91 \mathrm{pN}$, which is less than half of the value in water. The third rupture force is $170 \pm 42 \mathrm{pN}$, when Streptavidin is adsorbed on the $\mathrm{CH}_{3}$ long monolayer. Almost the same rupture forces are obtained when Streptavidin is adsorbed on $\mathrm{NH}_{3}{ }^{+}$and mix long monolayers, respectively $167 \pm 60$ $\mathrm{pN}$ and $166 \pm 47 \mathrm{pN}$. The lower rupture force is $129 \pm 38 \mathrm{pN}$ and corresponds to mix short monolayer.

As expected, the adsorption of Streptavidin on silane monolayers results in a decrease in the rupture force, i.e. a weakening of Streptavidin - Biotin interactions. This is due to conformational changes in Streptavidin, as shown by RMSD values which are systematically higher when Streptavidin is adsorbed on a surface, and by the higher number of residues with high flexibility. This is in agreement with recent study from Sedlak et al., which demonstrated that conformational 
changes due to Streptavidin attachment result in a lowering of the energy barrier to move Biotin out of the binding pocket and thus in a decrease of the rupture force. ${ }^{42}$

However, our results suggest that the conformational changes induced by the adsorption of Streptavidin on silane monolayer is much lower than on the crystalline graphite and $\mathrm{TiO}_{2}$ surfaces investigated previously. ${ }^{11}$ Indeed, our results suggest that the RMSD value of Streptavidin adsorbed on a silane monolayer is below $5 \AA$, whatever the silane monolayer studied, while it was demonstrated that Streptavidin is spreading over crystalline surfaces and that its secondary and tertiary structures are greatly reduced, as explain above, with RMSD values in the range 15 - 40 $\AA .{ }^{11}$ Furthermore, it was shown that Streptavidin loses its ability to bind with Biotin when it is adsorbed on crystalline $\mathrm{TiO}_{2}$ and graphite surfaces. Indeed, the Biotin binding site is destroyed, the location of its components is moved from Streptavidin interior to exterior. On the contrary, Streptavidin - Biotin binding potential is preserved when Streptavidin is immobilized on the silane monolayers studied.

The higher rupture forces are obtained when Streptavidin is adsorbed on uncharged silane monolayers $\mathrm{CH}_{3}$ short and $\mathrm{CH}_{3}$ long. The $\mathrm{CH}_{3}$ short silane monolayer leads to the closest value to the system in water. It corresponds to the system with the lowest RMSD and only 4 residues with high flexibility, none of them being located in the binding pocket. Thus, the lowest Streptavidin conformational change is induced with adsorption on $\mathrm{CH}_{3}$ short monolayer and allows to better preserve Streptavidin - Biotin interactions. The lower rupture force for $\mathrm{CH}_{3}$ long monolayer is explained by the higher RMSD value, which is related to high total VdW and elec interaction energy. Indeed, numerous Van der Waals interactions are established between Streptavidin and long alkyl chains of silane molecules. 
The smallest rupture forces and unbinding times are obtained for the charged monolayers mix short, mix long and $\mathrm{NH}_{3}{ }^{+}$. In all cases, the weakening of Streptavidin - Biotin binding is explained by the strong conformational changes in Streptavidin. $\mathrm{NH}_{3}{ }^{+}$monolayer induces the highest RMSD value, i.e. the strongest global conformational change. This is due to strong electrostatic interactions between $\mathrm{NH}_{3}{ }^{+}$silane molecules and Streptavidin. Negatively charged residues interact preferentially with the positively charged silane molecules, whereas non-polar and positively charged residues are repulsed away from the surface.

Regarding mix long and mix short monolayers, the value of the rupture force is not directly correlated to the RMSD value and the number of residues with high flexibility. However, for both mixed monolayers, a high flexibility is shown by residues 48Gly and 49Asn from chain $A$, which belong to the loop 3-4 of the binding pocket and are in direct contact with Biotin. This local conformational change induces a weakening of Streptavidin - Biotin interactions and results in lower rupture force for both systems. Indeed, the essential role of 48Gly and 49Asn in binding with Biotin was already demonstrated. Especially, Asn49 shows the highest individual cooperativity with other residues from the binding pocket to interact with Biotin. ${ }^{58}$

To summarize, we obtain the highest rupture force for the system in water, which means that Streptavidin adsorption on silane monolayer systematically induces a weakening of Streptavidin Biotin interactions. The lower rupture force values are obtained for the charged surfaces $\mathrm{NH}_{3}{ }^{+}$, mix short and mix long. Regarding $\mathrm{NH}_{3}{ }^{+}$monolayer, the reduction of interactions with Biotin is explained by the strong global conformation changes in Streptavidin. Regarding mixed monolayers, interactions with surface induce a local conformational change in the binding pocket, which affects interactions with Biotin. Higher rupture forces are obtained with neutral silane monolayers $\mathrm{CH}_{3}$ long and $\mathrm{CH}_{3}$ short. Thus, Streptavidin conformational changes induced by Van 
der Waals interactions with silane molecules seem to better preserve Streptavidin - Biotin binding properties. However, the rupture force is lower for $\mathrm{CH}_{3}$ long monolayer than for $\mathrm{CH}_{3}$ short. This is due to larger contact area with Streptavidin, which results in higher total VdW and elec interaction energy and stronger conformational changes.

\section{CONCLUSION}

In this work, we focus on the impact of different silane monolayers, on Streptavidin adsorption and on its interactions with Biotin. Our study reveals that the adsorption mechanism is modified by the head-group charge and by the alkyl-chain length of silane molecules. With $\mathrm{NH}_{3}{ }^{+}$silane monolayer, contact surface is very low. Only two negatively charged amino acids are likely to interact with silane molecules, while positively charged and hydrophobic amino acids are repulsed away from the surface. On the contrary, $\mathrm{CH}_{3}$ short and $\mathrm{CH}_{3}$ long silane monolayers induce Van der Waals interactions with numerous Streptavidin residues and large contact area, especially for $\mathrm{CH}_{3}$ long silane monolayer, due to long alkyl chains. Consequently, adsorption on surface induces different conformational changes in Streptavidin, depending on silane monolayer. In particular, Streptavidin encounters conformational changes close to the binding pocket when it is adsorbed on mixed monolayers.

We perform SMD simulation on all systems. Biotin is pulled away while Van der Waals and electrostatic interactions keep Streptavidin immobilized on surface. We show that adsorptioninduced conformational changes in Streptavidin lead to a strong modification of Streptavidin Biotin interactions. For all silane monolayers, the rupture force is 2-fold to 4-fold lower than for the system in water. The rupture force, that is the closest to the system in water without surface, is obtained with $\mathrm{CH}_{3}$ short monolayer, which is also the one with the lowest RMSD and the fewest 
residues with high mobility. Therefore, since $\mathrm{CH}_{3}$ short monolayer seems to preserve better the Streptavidin - Biotin interactions, it would be the most appropriate to non-covalently immobilize Streptavidin, while keeping its ability to strongly interact with Biotin. This study reveals that some specific silane monolayers allow Streptavidin immobilization, with high adsorption energy, while keeping the Biotin interactions. These findings could be extrapolated to other protein systems, such as cancer or virus antibodies for the design of diagnosis tools with higher efficiency and simplified experimental protocols.

\section{ASSOCIATED CONTENT}

The following Supporting Information is available free of charge.

Force-field parameters for the description of amorphous $\mathrm{SiO}_{2}$ layer and silane molecules.

Electrostatic potential on the Streptavidin molecular surface. Streptavidin adsorption on different silane monolayers (Interaction energy between Streptavidin and the silane monolayers, Interactions between Streptavidin and $\mathrm{SiO}_{2}$ ). Conformational changes in Streptavidin: RMSF traces. SMD simulations: pulling direction. (PDF)

Movie S1. Video of representative SMD simulation of Biotin unbinding at pulling velocity of $2 \mathrm{~m} / \mathrm{s}$ with Streptavidin in water (AVI)

Movie S2. Video of representative SMD simulation of Biotin unbinding at pulling velocity of $2 \mathrm{~m} / \mathrm{s}$ with Streptavidin adsorbed on $\mathrm{CH}_{3}$ short silane monolayer (AVI)

Movie S3. Video of representative SMD simulation of Biotin unbinding at pulling velocity of $2 \mathrm{~m} / \mathrm{s}$ with Streptavidin adsorbed on $\mathrm{CH}_{3}$ long silane monolayer (AVI) 
Movie S4. Video of representative SMD simulation of Biotin unbinding at pulling velocity of $2 \mathrm{~m} / \mathrm{s}$ with Streptavidin adsorbed on $\mathrm{NH}_{3}{ }^{+}$silane monolayer (AVI)

Movie S5. Video of representative SMD simulation of Biotin unbinding at pulling velocity of $2 \mathrm{~m} / \mathrm{s}$ with Streptavidin adsorbed on mix long silane monolayer (AVI)

Movie S6. Video of representative SMD simulation of Biotin unbinding at pulling velocity of $2 \mathrm{~m} / \mathrm{s}$ with Streptavidin adsorbed on mix short silane monolayer (AVI)

\section{AUTHOR INFORMATION}

\section{Author Contributions}

The manuscript was written through contributions of all authors. All authors have given approval to the final version of the manuscript.

\section{Funding Sources}

This work was supported by the Young Researcher ANR PORIDG project, grant ANR-18-CE090006 of the French Agence Nationale de la Recherche. This work was granted access to the HPC resources of CINES under the allocation 2019-A0070711100 made by GENCI.

\section{ACKNOWLEDGMENT}

This work was supported by the PMCS2I - supercomputer Newton from Ecole Centrale de Lyon, France, member of the FLMSN. The authors thank Laurent Pouilloux, Anne Cadiou, and Laurent Carrel for support on PMCS2I resources. 


\section{REFERENCES}

(1) Moon, J.; Byun, J.; Kim, H.; Jeong, J.; Lim, E. K.; Jung, J.; Cho, S.; Cho, W.K.; Kang, T. Surface-Independent and Oriented Immobilization of Antibody via One-Step Polydopamine/Protein G Coating: Application to Influenza Virus Immunoassay. Macromol. Biosci. 2019, 19, 1800486.

(2) Firkowska-Boden, I.; Zhang, X.; Jandt, K. D. Controlling Protein Adsorption through Nanostructured Polymeric Surfaces. Adv. Healthcare Mater. 2018, 7, 1700995.

(3) Zhang, Y.; Wu, C.; Guo, S.; Zhang, J. Interactions of Graphene and Graphene Oxide with Proteins and Peptides. Nanotechnol. Rev. 2013, 2, 27-45.

(4) Kidoaki, S.; Matsuda, T. Adhesion Forces of the Blood Plasma Proteins on Self-Assembled Monolayer Surfaces of Alkanethiolates with Different Functional Groups Measured by an Atomic Force Microscope. Langmuir 1999, 15, 7639-7646.

(5) Margel, S.; Vogler, E. A.; Firment, L.; Watt, T.; Haynie, S.; Sogah, D. Y. Peptide, Protein, and Cellular Interactions with Self-Assembled Monolayer Model Surfaces. J. Biomed. Mater. Res. 1993, 27, 1463-1476.

(6) Yang, Z.; Chevolot, Y.; Gehin, T.; Dugas, V.; Xanthopoulos, N.; Laporte, V.; Delair, T.; Ataman-Önal, Y.; Choquet-Kastylevsky, G.; Souteyrand, E.; et al. Characterization of Three Amino-Functionalized Surfaces and Evaluation of Antibody Immobilization for the Multiplex Detection of Tumor Markers Involved in Colorectal Cancer. Langmuir 2013, 29, 1498-1509.

(7) Yang, Z.; Chevolot, Y.; Gehin, T.; Solassol, J.; Mange, A.; Souteyrand, E.; Laurenceau, E. Improvement of Protein Immobilization for the Elaboration of Tumor-Associated Antigen Microarrays: Application to the Sensitive and Specific Detection of Tumor Markers from Breast Cancer Sera. Biosens. Bioelectron. 2013, 40, 385-392. 
(8) Ozboyaci, M.; Kokh, D. B.; Corni, S.; Wade, R. C. Modeling and Simulation of Protein-Surface Interactions: Achievements and Challenges. Q. Rev. Biophys. 2016, 49, e4.

(9) Hagiwara, T.; Sakiyama, T.; Watanabe, H. Molecular Simulation of Bovine $\beta$-Lactoglobulin Adsorbed onto a Positively Charged Solid Surface. Langmuir 2009, 25, 226-234.

(10) Hoefling, M.; Monti, S.; Corni, S.; Gottschalk, K. E. Interaction of $\beta$-Sheet Folds with a Gold Surface. PloS one 2011, 6, e20925.

(11) Mücksch, C.; Urbassek, H. M. Accelerated Molecular Dynamics Study of the Effects of Surface Hydrophilicity on Protein Adsorption. Langmuir 2016, 32, 9156-9162.

(12) Tokarczyk, K.; Kubiak-Ossowska, K.; Jachimska, B.; Mulheran, P. A. Energy Landscape of Negatively Charged BSA Adsorbed on a Negatively Charged Silica Surface. J. Phys. Chem. B 2018, 122, 3744-3753.

(13) Patwardhan, S. V.; Emami, F. S.; Berry, R. J.; Jones, S. E.; Naik, R. R.; Deschaume, O.; Heinz, H.; Perry, C. C. Chemistry of Aqueous Silica Nanoparticle Surfaces and the Mechanism of Selective Peptide Adsorption. J. Am. Chem. Soc. 2012, 134, 6244-6256.

(14) Tosaka, R.; Yamamoto, H.; Ohdomari, I.; Watanabe, T. Adsorption Mechanism of Ribosomal Protein L2 onto a Silica Surface: a Molecular Dynamics Simulation Study. Langmuir 2010, 26, $9950-9955$.

(15) Mazouz, Z.; Mokni, M.; Fourati, N.; Zerrouki, C.; Barbault, F.; Seydou, M.; Kalfat, R.; Yaakoubi, N.; Omezzine, A.; Bouslema, A.; et al. Computational Approach and Electrochemical Measurements for Protein Detection with MIP-Based Sensor. Biosens. Bioelectron. 2020, 151, 111978. 
(16) O’Mahony, S.; O’Dwyer, C.; Nijhuis, C. A.; Greer, J. C.; Quinn, A. J.; Thompson, D. Nanoscale Dynamics and Protein Adhesivity of Alkylamine Self-Assembled Monolayers on Graphene. Langmuir 2013, 29, 7271-7282.

(17) Ruan, M.; Seydou, M.; Noel, V.; Piro, B.; Maurel, F.; Barbault, F. Molecular Dynamics Simulation of a RNA Aptasensor. J. Phys. Chem. B 2017, 121, 4071-4080.

(18) Utesch, T.; Millo, D.; Castro, M. A.; Hildebrandt, P.; Zebger, I.; Mroginski, M. A. Effect of the Protonation Degree of a Self-Assembled Monolayer on the Immobilization Dynamics of a [NiFe] Hydrogenase. Langmuir 2013, 29, 673-682.

(19) Wang, Q.; Zhao, J.; Yu, X.; Zhao, C.; Li, L.; Zheng, J. Alzheimer A $\beta 1-42$ Monomer Adsorbed on the Self-Assembled Monolayers. Langmuir 2010, 26, 12722-12732.

(20) Wang, Q.; Zhao, C.; Zhao, J.; Wang, J.; Yang, J. C.; Yu, X.; Zheng, J. Comparative Molecular Dynamics Study of A $\beta$ Adsorption on the Self-Assembled Monolayers. Langmuir 2010, 26, 33083316.

(21) Xie, Y.; Liu, M.; Zhou, J. Molecular Dynamics Simulations of Peptide Adsorption on SelfAssembled Monolayers. Appl. Surf. Sci. 2012, 258, 8153-8159.

(22) Hsu, H. J.; Sheu, S. Y.; Tsay, R. Y. Preferred Orientation of Albumin Adsorption on a Hydrophilic Surface from Molecular Simulation. Colloids Surf., B 2008, 67, 183-191.

(23) Nordgren, C. E.; Tobias, D. J.; Klein, M. L.; Blasie, J. K. Molecular Dynamics Simulations of a Hydrated Protein Vectorially Oriented on Polar and Nonpolar Soft Surfaces. Biophys. J. 2002, 83, 2906-2917.

(24) Sun, Y.; Welsh, W. J.; Latour, R. A. Prediction of the Orientations of Adsorbed Protein Using an Empirical Energy Function with Implicit Solvation. Langmuir 2005, 21, 5616-5626. 
(25) Tobias, D. J.; Mar, W.; Blasie, J. K.; Klein, M. L. Molecular Dynamics Simulations of a Protein on Hydrophobic and Hydrophilic Surfaces. Biophys. J. 1996, 71, 2933-2941.

(26) Hitaishi, V. P.; Clement, R.; Bourassin, N.; Baaden, M.; De Poulpiquet, A.; Sacquin-Mora, S.; Ciaccafava, A.; Lojou, E. Controlling Redox Enzyme Orientation at Planar Electrodes. Catalysts 2018, 8, 192.

(27) Xie, Y.; Gong, W.; Jin, J.; Zhao, Z.; Li, Z.; Zhou, J. Molecular Simulations of Lysozyme Adsorption on an Electrically Responsive Mixed Self-Assembled Monolayer. Appl. Surf. Sci. 2020, 506, 144962.

(28) Grubmüller, H.; Heymann, B.; Tavan, P. Ligand Binding: Molecular Mechanics Calculation of the Streptavidin-Biotin Rupture Force. Science 1996, 271, 997-999.

(29) Izrailev, S.; Stepaniants, S.; Balsera, M.; Oono, Y.; Schulten, K. Molecular Dynamics Study of Unbinding of the Avidin-Biotin Complex. Biophys. J. 1997, 72, 1568-1581.

(30) Liu, F.; Zhang, J. Z.; Mei, Y., The Origin of the Cooperativity in the Streptavidin-Biotin System: A Computational Investigation through Molecular Dynamics Simulations. Sci. Rep. 2016, 6. 27190.

(31) Song, J.; Li, Y.; Ji, C.; Zhang, J. Z. Functional Loop Dynamics of the Streptavidin-Biotin Complex. Sci. Rep. 2015, 5, 7906.

(32) Moy, V. T.; Florin, E. L.; Gaub, H. E. Intermolecular Forces and Energies Between Ligands and Receptors. Science 1994, 266, 257-259.

(33) Hinterdorfer, P.; Dufrêne, Y. F. Detection and Localization of Single Molecular Recognition Events Using Atomic Force Microscopy. Nat. Methods 2006, 3, 347-355.

(34) Woodside, M. T.; Block, S. M. Reconstructing Folding Energy Landscapes by SingleMolecule Force Spectroscopy. Annu. Rev. Biophys. 2014, 43, 19-39. 
(35) Lee, C. K.; Wang, Y. M.; Huang, L.S.; Lin, S. Atomic Force Microscopy: Determination of Unbinding Forces, Off Rate and Energy Barrier for Protein-Ligand Interaction. Micron 2007, 38, $446-461$.

(36) Köhler, M.; Karner, A.; Leitner, M.; Hytönen, V.P.; Kulomaa, M.; Hinterdorfer, P.; Ebner, A. pH-Dependent Deformations of the Energy Landscape of Avidin-Like Proteins Investigated by Single Molecule Force Spectroscopy. Molecules 2014, 19, 12531-12546.

(37) Sedlak, S. M.; Bauer, M. S.; Kluger, C.; Schendel, L. C.; Milles, L. F.; Pippig, D. A.; Gaub, H. E. Monodisperse Measurement of the Biotin-Streptavidin Interaction Strength in a WellDefined Pulling Geometry. PloS one 2017, 12, e0188722.

(38) Li, J.; Li, Q.; Potthoff, S.; Wei, G.; Lucio, C. C. Force Spectroscopic Detection of Peptide Cleavage by Thrombin Exploiting Biotin-Streptavidin Interactions in a Bio-Sensing Context. Anal. Methods 2019, 11, 1102-1110.

(39) Rico, F.; Russek, A.; Gonzalez, L.; Grubmüller, H.; Scheuring, S. Heterogeneous and RateDependent Streptavidin-Biotin Unbinding Revealed by High-Speed Force Spectroscopy and Atomistic Simulations. Proc. Natl. Acad. Sci. U. S. A. 2019, 116, 6594-6601.

(40) Merkel, R.; Nassoy, P.; Leung, A.; Ritchie, K.; Evans, E. Energy Landscapes of ReceptorLigand Bonds Explored with Dynamic Force Spectroscopy. Nature 1999, 397, 50-53.

(41) Sedlak, S. M.; Schendel, L. C.; Melo, M. C.; Pippig, D. A.; Luthey-Schulten, Z.; Gaub, H. E.; Bernardi, R. C. Direction Matters: Monovalent Streptavidin/Biotin Complex under Load. Nano Lett. 2018, 19, 3415-3421.

(42) Sedlak, S. M.; Schendel, L. C.; Gaub, H. E.; Bernardi, R. C. Streptavidin/Biotin: Tethering Geometry Defines Unbinding Mechanics. Sci. Adv. 2020, 6, eaay5999. 
(43) Le Trong, I.; Wang, Z.; Hyre, D. E.; Lybrand, T. P.; Stayton, P. S.; Stenkamp, R. E. Streptavidin and its Biotin Complex at Atomic Resolution. Acta Crystallogr., Sect. D: Biol. Crystallogr. 2011, 67, 813-821.

(44) Jorgensen, W. L.; Maxwell, D. S.; Tirado-Rives, J. Development and Testing of the OPLS All-Atom Force Field on Conformational Energetics and Properties of Organic Liquids. J. Am. Chem. Soc. 1996, 118, 11225-11236.

(45) Malde, A.K.; Zuo, L.; Breeze M.; Stroet, M.; Poger, D.; Nair, P.C.; Oostenbrink, C.; Mark, A.E. An Automated Force Field Topology Builder (ATB) and Repository: version 1.0. J. Chem. Theory Comput. 2011, 7, 4026-4037.

(46) Stroet, M.; Caron, B.; Visscher, K. M.; Geerke, D. P.; Malde, A. K.; Mark, A. E. Automated Topology Builder Version 3.0: Prediction of Solvation Free Enthalpies in Water and Hexane. $J$. Chem. Theory Comput. 2018, 14, 5834-5845.

(47) Roscioni, O. M.; Muccioli, L.; Mityashin, A.; Cornil, J.; Zannoni, C. Structural Characterization of Alkylsilane and Fluoroalkylsilane Self-Assembled Monolayers on SiO2 by Molecular Dynamics Simulations. J. Phys. Chem. C 2016, 120, 14652-14662.

(48) Castillo, J. M.; Klos, M.; Jacobs, K.; Horsch, M.; Hasse, H. Characterization of Alkylsilane Self-Assembled Monolayers by Molecular Simulation. Langmuir 2015, 31, 2630-2638.

(49) Abascal, J. L.; Vega, C. A General Purpose Model for the Condensed Phases of Water: TIP4P/2005. J. Chem. Phys. 2005, 123, 234505.

(50) Kitabata, M.; Taddese, T.; Okazaki, S. Molecular Dynamics Study on Wettability of Poly (vinylidene fluoride) Crystalline and Amorphous Surfaces. Langmuir 2018, 34, 12214-12223.

(51) Van Der Spoel, D.; Lindahl, E.; Hess, B.; Groenhof, G.; Mark, A. E.; Berendsen, H. J. GROMACS: Fast, Flexible, and Free. J. Comput. Chem. 2005, 26, 1701-1718. 
(52) Humphrey, W.; Dalke, A.; Schulten, K. VMD: Visual Molecular Dynamics. J. Mol. Graphics 1996, 14, 33-38.

(53) Darden, T.; York, D.; Pedersen, L. Particle Mesh Ewald: An N·log (N) Method for Ewald Sums in Large Systems. J. Chem. Phys. 1993, 98, 10089-10092.

(54) Júnior, M. F. F.; Franca, E. F.; Leite, F. L. Unbinding Pathway Energy of Glyphosate from the EPSPs Enzyme Binding Site Characterized by Steered Molecular Dynamics and Potential of Mean Force. J. Mol. Graphics Modell. 2017, 72, 43-49.

(55) Tang, P.; Xu, Y. Large-Scale Molecular Dynamics Simulations of General Anesthetic Effects on the Ion Channel in the Fully Hydrated Membrane: the Implication of Molecular Mechanisms of General Anesthesia. Proc. Natl. Acad. Sci. U. S. A. 2002, 99, 16035-16040.

(56) Kamal, M. Z.; Mohammad, T. A. S.; Krishnamoorthy, G.; Rao, N. M. Role of Active Site Rigidity in Activity: MD Simulation and Fluorescence Study on a Lipase Mutant. PLoS One 2012, 7, e35188.

(57) Espinoza-Fonseca, L. M.; Trujillo-Ferrara, J. G. Conformational Changes of the p53-Binding Cleft of MDM2 Revealed by Molecular Dynamics Simulations. Biopolymers 2006, 83, 365-373. (58) Cong, Y.; Huang, K.; Li, Y.; Zhong, S.; Zhang, J. Z.; Duan, L. Entropic Effect and Residue Specific Entropic Contribution to the Cooperativity in Streptavidin-Biotin Binding. Nanoscale 2020, 12, 7134-7145. 


\section{TOC GRAPHIC}

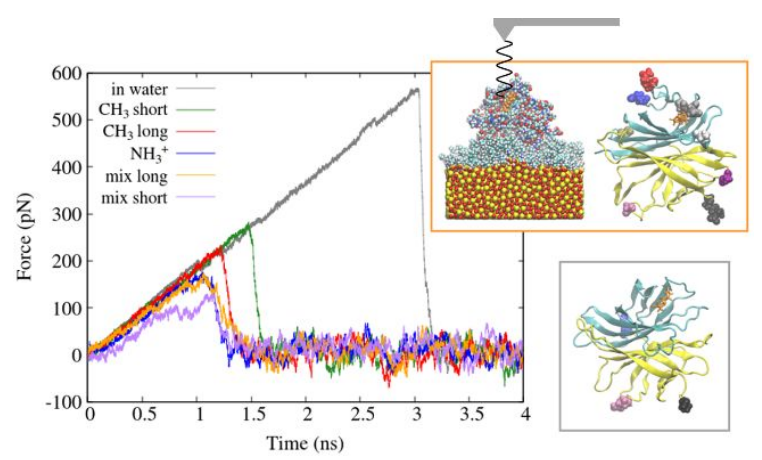

